\title{
ACOLHIMENTO E ASSISTÊNCIA DE ENFERMAGEM ÀS MULHERES VÍTIMAS DE VIOLÊNCIA DOMÉSTICA: UMA REVISÃO INTEGRATIVA
}

\section{HOSPITALIZATION OF NURSING WOMEN VICTIMS OF DOMESTIC VIOLENCE: AN INTEGRATIVE REVIEW}

\author{
Amanda Maria Villas Bôas Ribeiro, Iracema Santos da Silva Baldoino
}

Faculdade Metropolitana de Camaçari

\begin{abstract}
In view of the magnitude and repercussions of violence in the woman's life, this review was carried out on the reception and nursing care for women victims of domestic violence. A search was made in the Scielo and Lilacs databases based on the Health Science descriptors: Women, Domestic Violence, Nursing, Reception, with the help of the Boolean operator AND. From the eight selected articles, it was demonstrated the importance of nursing care for women victims of violence. However, it became evident that nursing professionals, in general, are still unprepared to assist women victims of domestic violence in a welcoming and humanized way, thus failing to guarantee the right to health in an integral way. Thus, it is understood that this study points to the urgency to carry out in practice, the training of nursing professionals and all health professionals. Investment in a multidisciplinary team is needed to assist and direct victims to safe and comfortable places.
\end{abstract}

Key words: Domestic violence. Woman. Nursing Reception.

\section{Resumo}

Diante da magnitude e repercussões da violência na vida da mulher, realizou-se a presente revisão sobre $o$ acolhimento $e$ assistência de enfermagem às mulheres vítimas de violência doméstica. Foi feita busca nas bases de dados Scielo e Lilacs a partir dos descritores em Ciências em Saúde: Mulher, Violência Doméstica, Enfermagem, Acolhimento, com auxílio do operador booleano AND. A partir dos oito artigos selecionados foi demonstrada a importância do acolhimento de enfermagem à mulher vítima de violência. Contudo, evidenciou-se que os profissionais de enfermagem, no geral, ainda estão despreparados para atender às mulheres vítimas de violência doméstica de forma acolhedora e humanizada, deixando assim de garantir o direito à saúde de forma integral. Desta forma, entende-se que este estudo aponta para a urgência de se efetivar na prática, a capacitação de profissionais de enfermagem $e$ todos os profissionais da área de saúde. É necessário investimento em equipe multidisciplinar que atenda e direcione as vítimas a locais seguros e confortáveis.

Palavras-chave: Violência Doméstica. Mulher. Acolhimento de Enfermagem. 


\section{Introdução}

A violência contra a mulher é um ato desumano e cruel, consiste em qualquer ação que fere sua integridade física, sexual e psicológica, incluindo ameaças Dentre as formas de violência contra mulher, destaca-se a violência doméstica que é cometida, muitas vezes, pelo cônjuge, parente ou pessoas que convive com a vítima $^{1}$.

O contexto histórico de violência contra a mulher é resultado de uma relação de hierarquia de poder, em que a mulher é vista como submissa, muito em virtude da desigualdade de gênero construída socialmente entre homens e mulheres².

A violência doméstica é um problema que assombra e atinge mulheres de todas as idades, independente de classe social, cultura, grau de instrução, etnia e grau de desenvolvimento. Estima-se que um em cada três mulheres já sofreram algum tipo de violência durante a vida podendo ser física, psicológica, sexual ou moral, cometida pelo seu companheiro, excompanheiro ou pessoa próxima a ela ${ }^{3}$.

Os atos de violência doméstica podem se prolongar durante anos, trazendo prejuízo irreparável para saúde da vítima. No Brasil, a alta prevalência de caso de violência doméstica tem se tornado um problema de saúde pública, pois, diversos fatores estão ligados a esse tipo de violência, como o uso abusivo de álcool pelo parceiro, baixo nível econômico e dependência financeira da vítima ao agressor ${ }^{4}$.

Desde a criação da Lei $n^{\circ} 11.340$ conhecida como lei Maria da Penha de 22 de setembro de 2006, que tem objetivo de punir e coibir o agressor houve um aumento de denúncia dos casos de violência doméstica por parte das vítimas ${ }^{5}$.

O Brasil possui uma taxa muito alta de homicídios, ocorrendo cerca 4,8 de por cada 100 mil mulheres. Em grupo de 83 países, ocupando assim 5a posição o que mostra alta incidência de casos de violências se comparados aos encontrados em outros países. Entre 2003 e 2013, o número de vítimas do sexo feminino passou de 3.937 para 4.762 , incremento de $21 \%$ o que representou 13 homicídios femininos diários em $2013^{6}$.

As mulheres que sofrem violência procuram atendimento no sistema único de saúde (SUS).
Desde março de 2003 está em vigor no Brasil, a Lei $n^{\circ} 10.778$ de 24/11/2003 de notificação compulsória que deixa claro que todo caso de atendimento a mulher vítima de violência deve ser notificado, sendo ele em instituição pública ou privada. Mesmo diante da lei, ainda se nota pouco preparo por parte da equipe de enfermagem, de como agir diante dos atendimentos a vítima de violência doméstica e pouco conhecimento sobre as ações ${ }^{7}$.

O primeiro atendimento da mulher vítima de violência acontece na (UPA) Unidade de Pronto Atendimento ou Estratégia de Saúde da Família (ESF) com profissional de enfermagem que deve prestar atendimento humanizado, realizar avaliação, marcar consulta, acolher, orientar sobre seus direitos, prestar esclarecimento, como pode ser feita a denúncia, o enfermeiro deve ter conhecimento sobre a delegacia especializada no atendimento a mulher e também núcleo de apoio assistencial ${ }^{1}$.

Os cuidados de enfermagem são fundamentais uma vez que a vítima se encontra fragilizada e desamparada diante da situação. Diante da magnitude epidemiológica e repercussões na vida das mulheres vítimas de violência doméstica destaca-se a necessidade de evidenciar a importância do acolhimento e da assistência de enfermagem às vítimas de violência doméstica ${ }^{8}$.

Portanto, a questão de pesquisa é: Quais as evidências científicas acerca do acolhimento e assistência de enfermagem às mulheres vítimas de violência doméstica? Assim, o objetivo do estudo é analisar as evidências científicas acerca do acolhimento e assistência de enfermagem às mulheres vítimas de violência doméstica.

\section{Materiais e Métodos}

Trata-se de um estudo bibliográfico, do tipo revisão de literatura integrativa sobre o acolhimento e assistência de enfermagem às mulheres vítimas de violência doméstica. Este tipo de estudo possibilita elaborar uma síntese do conhecimento produzido para subsidiar a tomada de decisão clínica e assistencial.

Para estruturação desta revisão percorreram-se algumas etapas: (1) identificação do tema e elaboração da pergunta de pesquisa; (2) busca na literatura; (3) categorização dos estudos; (4) avaliação dos estudos incluídos; (5) 
interpretação dos resultados; (6) redação e publicação dos resultados obtidos.

Assim, elaborou-se a seguinte pergunta: Quais as evidências científicas acerca do acolhimento e assistência de enfermagem às mulheres vítimas de violência doméstica?

A busca foi realizada nas bases de dados Scientific Eletronic Library Online (SciELO), Medical Literature Analysis and Retrieval System Online (MEDLINE) e Literatura Latino-Americana e Caribe em Ciência da Saúde (LILACS). Foram utilizados Descritores em Ciências da Saúde (DeCS): Mulher, Violência Doméstica, Enfermagem, Acolhimento.Para proporcionar uma maior delimitação na busca, foi realizada uma intercessão entre os DeCS com o operador booleano "AND".

Os critérios de inclusão dos artigos foram: estudos publicados entre 2014 a 2019 na língua portuguesa; ser artigo original; com disponibilidade do texto na íntegra nas bases de dados selecionadas, e que atendessem ao objeto de estudo delimitado. Foram excluídos artigos repetidos, livros, teses, dissertações, cartas, jornais, resenhas, e artigos não originais e que não tivesse disponibilidade online gratuita.

\section{Resultados e Discussão}

Selecionaram-se, inicialmente, 200 artigos, dados excluídos 155 por não tratar do objeto em estudo. Assim, foi realizada leitura completa de 45 artigos elegíveis e excluídos 34 pelas seguintes razões: não de tratava de violência doméstica e acolhimento de enfermagem (15), abordagem da violência doméstica como caso de polícia (13) e abordagem legal da violência doméstica (8).

Assim, neste estudo foram analisados 9 artigos (Quadro 1) publicados no período de 2014 a 2019, sendo 1 de revisão literatura, 8 estudos de pesquisa qualitativa.

Quadro 1: Síntese de artigos selecionados na base de dados

\begin{tabular}{|c|c|c|c|c|c|}
\hline $\begin{array}{l}\text { № } \\
1\end{array}$ & ARTIGO & $\begin{array}{c}\text { AUTOR/ } \\
\text { ANO }\end{array}$ & PERÍODICO & OBJETIVO (S) & CONSIDERAÇÕES \\
\hline & $\begin{array}{lr}\text { Assistência } & \text { à } \\
\text { saúde } & \text { da } \\
\text { mulher } & \text { em } \\
\text { situação } & \text { de } \\
\text { violência } & \\
\text { domestica. } & \\
\text { Revisão } & \\
\text { Integrativa } & \end{array}$ & $\begin{array}{l}\text { Rodrigues et } \\
\text { al. } \\
2018\end{array}$ & $\begin{array}{l}\text { Rev. } \\
\text { Saude.Com }\end{array}$ & $\begin{array}{l}\text { Analisar a assistência à } \\
\text { saúde da mulher em } \\
\text { situação de violência } \\
\text { doméstica abordada nas } \\
\text { produções científicas } \\
\text { publicadas no período } \\
\text { de } 2005 \text { a } 2015 \text {. }\end{array}$ & $\begin{array}{l}\text { Os estudos apontaram } \\
\text { ainda que é necessário } \\
\text { capacitar os } \\
\text { profissionais de saúde } \\
\text { na identificação e no } \\
\text { cuidado à mulher em } \\
\text { situação de violência, já } \\
\text { que eles encontram-se } \\
\text { despreparados, visto } \\
\text { que a temática é pouco } \\
\text { abordada. }\end{array}$ \\
\hline 2 & $\begin{array}{l}\text { Atuação da } \\
\text { enfermagem } \\
\text { na conservação } \\
\text { da saúde das } \\
\text { mulheres em } \\
\text { situação de } \\
\text { violência. }\end{array}$ & $\begin{array}{l}\text { Neto et al. } \\
2018\end{array}$ & $\begin{array}{l}\text { REME.Rev.Mim } \\
\text { Efermagem. }\end{array}$ & $\begin{array}{l}\text { Analisar, pela ótica da } \\
\text { Teoria de Enfermagem } \\
\text { de Levine, o } \\
\text { atendimento da } \\
\text { enfermeira às mulheres } \\
\text { que sofreram violência. }\end{array}$ & $\begin{array}{l}\text { A violência está } \\
\text { presente no contexto } \\
\text { da família. O desafio } \\
\text { para as enfermeiras é } \\
\text { buscar uma rede social } \\
\text { para a mulher em uma } \\
\text { comunidade carente de } \\
\text { recursos econômicos e } \\
\text { sociais, para isso se faz } \\
\text { importante considerar a } \\
\text { multidisciplinaridade do } \\
\text { atendimento. }\end{array}$ \\
\hline
\end{tabular}




\begin{tabular}{|c|c|c|c|c|c|}
\hline 3 & $\begin{array}{l}\text { A } \\
\text { sistematização } \\
\text { da assistência } \\
\text { de } \\
\text { enfermagem } \\
\text { no } \\
\text { atendimento a } \\
\text { mulher vitima } \\
\text { de violência. }\end{array}$ & $\begin{array}{l}\text { Batista et al. } \\
2018\end{array}$ & $\begin{array}{l}\text { Rev.Caderno de } \\
\text { Graduação. }\end{array}$ & $\begin{array}{l}\text { É identificar as } \\
\text { consequências da } \\
\text { violência na saúde das } \\
\text { mulheres e definir os } \\
\text { principais Diagnósticos } \\
\text { de Enfermagem, } \\
\text { baseado nas } \\
\text { sintomatologias } \\
\text { apresentadas, segundo } \\
\text { o North American } \\
\text { Nursing Diagnosis } \\
\text { Association. }\end{array}$ & $\begin{array}{l}\text { Verificou-se que, para } \\
\text { efetivar um cuidado de } \\
\text { forma resolutiva, } \\
\text { voltado para as } \\
\text { necessidades } \\
\text { individuais de cada } \\
\text { mulher, é necessário o } \\
\text { planejamento } \\
\text { organização do } \\
\text { atendimento. Através } \\
\text { da SAE, o enfermeiro } \\
\text { tem a possibilidade de } \\
\text { organizar o cuidado } \\
\text { prestado, com ações } \\
\text { efetivas e direcionadas } \\
\text { para cada caso. }\end{array}$ \\
\hline 4 & $\begin{array}{l}\text { Atuação da } \\
\text { enfermagem } \\
\text { na identificão e } \\
\text { notificação dos } \\
\text { casos de } \\
\text { violência } \\
\text { doméstica. }\end{array}$ & $\begin{array}{l}\text { Freitas et al. } \\
2017\end{array}$ & $\begin{array}{l}\text { HU.Rev.Juiz de } \\
\text { Fora }\end{array}$ & $\begin{array}{l}\text { Compreender a atuação } \\
\text { dos enfermeiros na } \\
\text { identificação } \\
\text { notificação dos casos de } \\
\text { violência contra a } \\
\text { mulher, nas Unidades } \\
\text { de Pronto Atendimento } \\
\text { (UPA's). }\end{array}$ & $\begin{array}{l}\text { O profissional de } \\
\text { enfermagem tem um } \\
\text { papel relevante no } \\
\text { enfrentamento do } \\
\text { fenômeno, uma vez que } \\
\text { deveriam estar } \\
\text { envolvidos em todas as } \\
\text { etapas desenvolvidas } \\
\text { para o combate à } \\
\text { violência, desde a } \\
\text { prevenção até o } \\
\text { cuidado das vítimas, já } \\
\text { que é um profissional } \\
\text { que está inserido em } \\
\text { todos os níveis de } \\
\text { atenção em saúde. }\end{array}$ \\
\hline 5 & $\begin{array}{l}\text { Aspectos eticos } \\
\text { no cuidado de } \\
\text { enfermagem as } \\
\text { vitímas de } \\
\text { violência } \\
\text { doméstica. }\end{array}$ & $\begin{array}{l}\text { Acosta et al. } \\
2017\end{array}$ & $\begin{array}{l}\text { Texto Contexto } \\
\text { Enfermagem }\end{array}$ & $\begin{array}{l}\text { Analisar o } \\
\text { conhecimento de } \\
\text { enfermeiras } \\
\text { hospitalares sobre os } \\
\text { aspectos éticos e legais } \\
\text { no cuidado de } \\
\text { enfermagem às vítimas } \\
\text { de violência doméstica. }\end{array}$ & $\begin{array}{l}\text { A análise dos aspectos } \\
\text { éticos e legais que } \\
\text { permeiam o cuidado de } \\
\text { mulheres vítimas de } \\
\text { violência doméstica } \\
\text { permitiu concluir que } \\
\text { existem lacunas no } \\
\text { conhecimento das } \\
\text { enfermeiras acerca } \\
\text { dessas competências. } \\
\text { Considerando que os } \\
\text { hospitais são locais que } \\
\text { recebem os casos de } \\
\text { violência mais graves. }\end{array}$ \\
\hline
\end{tabular}




\begin{tabular}{|c|c|c|c|c|c|}
\hline 6 & $\begin{array}{l}\text { Violência } \\
\text { doméstica na } \\
\text { percepção de } \\
\text { enfermeiros de } \\
\text { serviço de } \\
\text { emergência. }\end{array}$ & $\begin{array}{l}\text { Peralva et al. } \\
2016\end{array}$ & $\begin{array}{l}\text { Rev. Portuguese } \\
\text { ReonFacema. }\end{array}$ & $\begin{array}{l}\text { Conhecer a percepção } \\
\text { do enfermeiro que atua } \\
\text { no serviço de } \\
\text { emergência hospitalar } \\
\text { sobre violência } \\
\text { doméstica. }\end{array}$ & $\begin{array}{l}\text { o profissional } \\
\text { enfermeiro consegue, } \\
\text { em sua maioria, } \\
\text { descrever o que é } \\
\text { violência doméstica, } \\
\text { porém nem sempre } \\
\text { essa percepção resulta } \\
\text { no entendimento do } \\
\text { tipo de violência } \\
\text { sofrida. }\end{array}$ \\
\hline 7 & $\begin{array}{l}\text { Formação } \\
\text { profissional e } \\
\text { notificação da } \\
\text { violência } \\
\text { contra } \\
\text { mulher. }\end{array}$ & $\begin{array}{l}\text { Cordeiro et al. } \\
2015\end{array}$ & $\begin{array}{l}\text { Rev. Baiana de } \\
\text { Enfermagem }\end{array}$ & $\begin{array}{l}\text { Identificar a relação } \\
\text { entre formação } \\
\text { profissional } \\
\text { notificação da violência } \\
\text { contra a mulher na } \\
\text { Estratégia de Saúde da } \\
\text { Família (ESF). Pesquisa } \\
\text { com abordagem } \\
\text { qualitativa, realizada } \\
\text { com } 35 \text { profissionais de } \\
\text { saúde em 20 UBS } \\
\text { Salvador, Bahia, Brasil. }\end{array}$ & 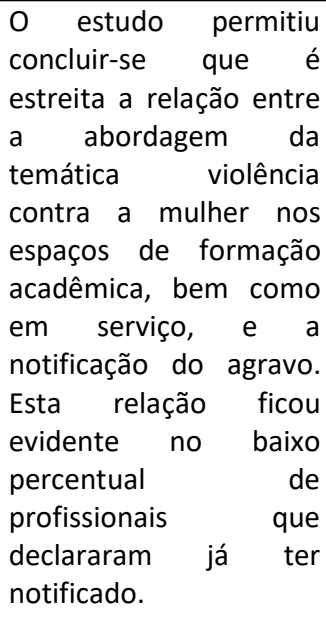 \\
\hline 8 & $\begin{array}{l}\text { Como os } \\
\text { profissionais de } \\
\text { saúde atendem } \\
\text { mulheres em } \\
\text { situação de } \\
\text { violência? Uma } \\
\text { análise } \\
\text { triangulada de } \\
\text { dados. }\end{array}$ & $\begin{array}{l}\text { Hasse et al. } \\
2014\end{array}$ & $\begin{array}{l}\text { Rev. } \\
\text { Saúde Debate }\end{array}$ & $\begin{array}{l}\text { Analisa o conhecimento } \\
\text { de profissionais sobre } \\
\text { violência contra a } \\
\text { mulher, e condutas e } \\
\text { encaminhamentos } \\
\text { realizados por eles, a } \\
\text { partir da análise } \\
\text { triangulada dos dados } \\
\text { de } 221 \text { questionários e } \\
23 \text { entrevistas, aplicados } \\
\text { a médicos e } \\
\text { enfermeiros. }\end{array}$ & 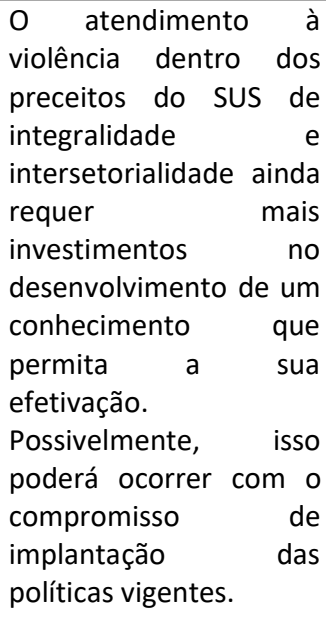 \\
\hline
\end{tabular}

$\mathrm{O}$ ato de violência contra a mulher acontece em diversos contextos, é um problema complexo que não distingue cor, raça, religião, ou classe social, afetando diretamente a saúde da mulher, tanto física como psicológica. Dentre os tipos de violência que acometem as mulheres, se 
destacam a violência doméstica, que ocorrem dentro de casa, de forma gradativa e silenciosa, podendo se perpetuar durante anos ${ }^{9}$.

A incidência de casos de violência doméstica se tornou crescente nos últimos anos, ele caracteriza pela relação de poder, dominação e autoritarismo, subjugando e humilhando a mulher, o que causa sofrimento físico e psicológico, sendo cometida por parceiro íntima, marido ou pessoa que tenha relação próxima a vitima. A violência sofrida deixa sequelas irreparáveis, sendo ela física ou psicológica afetando diretamente na saúde da mulher, em casos mais extremos podendo levar a morte decorrente de lesões e traumas físicos graves irreversíveis ${ }^{4}$

Papel da enfermagem no acolhimento a mulher em situação de violência doméstica

A violência contra mulher se tornou um problema de saúde pública ao longo dos anos, mas somente em 1990 a Organização Mundial de Saúde (OMS) reconheceu a violência contra mulher como um problema de saúde pública, que considera um desrespeito aos direitos humanos ${ }^{10}$.

Identifica-se que 0 ato de violência interfere diretamente na saúde da mulher com apresentações de doenças como: depressão, enxaqueca, insônia, dores crônicas, Infecção Sexualmente Transmissível, como também desenvolvem problemas psicológicos como irritabilidade, isolamento social, estresse póstraumático, em casos mais graves suicídio ${ }^{11}$.

Durante muitos anos se teve uma ideia equivocada que o problema de violência doméstica contra mulher pertence somente ao âmbito jurídico, é questão de segurança pública, tornando assim 0 atendimento apenas medicamentoso e curativo e de encaminhamento em caso mais graves sem se preocupar com o real motivo do adoecimento da mesma ${ }^{12}$.

A mulher que sofre violência busca por diversas vezes o serviço de saúde para tratar pequenas lesões e ferimentos. Neste contexto, a enfermagem que tem o primeiro contato com as vítimas, mas ainda se nota pouco preparo, de como agir diante da situação por parte dos profissionais de enfermagem ${ }^{10}$.

Os estudos destacaram que muitos profissionais de enfermagem ainda têm uma prática reducionista em seus atendimentos, baseada apenas no cuidado das lesões físicas, com ênfase na fisiopatologia, esquecendo-se por vezes que o corpo é integrado devendo levar em considerações aspectos psicológicos, sociais, conflito intrafamiliar, com episódio de violência doméstica interfere na saúde e qualidade de vida da mulher ${ }^{13}$.

O reconhecimento dos casos de violências contra mulher, como problema de saúde pública se dá pelas consequências diretas e indiretas na sua saúde, e espera dos profissionais de enfermagem uma postura acolhedora $e$ humanizada para com as vítimas ${ }^{7}$.

A enfermagem tem um papel importante no combate da violência doméstica, pois em grande número de casos, os enfermeiros que identificam sinais e sintomas sugestivos de violência doméstica já na classificação de risco no primeiro contato com a mulher ${ }^{14}$.

Diante dos casos violência doméstica a enfermagem deve prestar atendimento planejado, sistematizado, ter empatia, observar sinais de violência como cefaleia, dores musculares, emagrecimentos, pequenas lesões, cansaço, medo, isolamento social e depressão. 0 atendimento é pautado em conhecimento técnico e científico, mas são ações de responsabilidade dos enfermeiros prestar acolhimento humanizado, identificar o tipo de violência sofrido, notificar, fazer encaminhamento para o atendimento especializado e núcleo de prevenção à violência contra a mulher ${ }^{15}$.

$\mathrm{O}$ acolhimento de enfermagem as mulheres que sofrem violência doméstica, deve ser realizado respeitando suas particularidades. 0 enfermeiro precisa ter uma visão holística, não fazer julgamento, não expor a vítima a constrangimento, esclarecer seus direitos, reforçar que ela pode fazer a denúncia, explicar como funciona a medida protetiva, acionar o serviço social, estabelecer uma relação de confiança entre paciente e profissional ${ }^{16}$.

O cuidar faz parte do cotidiano dos profissionais de enfermagem, prestar assistência a pacientes vítimas de violências domésticas ainda é um desafio, pois muitos não se sentem preparados para lidar com situações de conflitos e medo por parte das vítimas. Portanto se faz necessário investimento por parte do poder público em uma equipe multidisciplinar que auxiliem no atendimento as vítimas ${ }^{9}$. 
A importância do acolhimento às mulheres vítimas de violência doméstica

A enfermagem tem um papel importante e crucial no atendimento à vítima de violência que se encontra fragilizada, desamparada e com medo, suas ações devem ser imediatas, reconhecendo a situação de violência, prestar atendimento de forma acolhedora, transmitindo confiança e conforto a mulher. As ações de enfermagem não devem se limitar apenas a um cuidado curativo, mas também requer uma educação contínua de que violência contra mulher é um crime que dever ser combatido por todos ${ }^{12}$.

A identificação dos casos de violência doméstica muitas vezes não é visível no primeiro contato, requer uma assistência mais cuidadosa como: coletas de dados, anamnese e exame físico. O cuidado a mulher deve ser planejado pelo enfermeiro promovendo segurança, confiança, respeito as suas necessidades, sigilos para não expor à mulher as demais pessoas ao seu redor, acionar o serviço social, fazer a notificação dos casos e denunciar o agressor ${ }^{7}$.

A notificação é uma ferramenta eficaz para avaliar o número de casos de violência doméstica contra mulher, porém, os estudos mostram que ainda há um despreparo por parte da equipe de enfermagem, de como realizar a notificação, e como agir para que a vítima não volte para o ambiente agressor, tornando a notificação dos casos deficientes, não sendo fidedigna a realidade vivenciada diariamente pelos enfermeiros na unidade de atendimento ${ }^{9}$.

Os estudos mostram que a principais dificuldades em formalizar a denúncia e notificar os casos, se da pela falta de conhecimento por parte da equipe de enfermagem o que afeta diretamente na qualidade da assistência, pois o enfermeiro tem o papel crucial porque em grande parte o primeiro contato da mulher vítima de violência doméstica se dá pela enfermagem. A formação do profissional de enfermagem não prepara para lidar com a questão da violência contra mulher, sendo um assunto ainda pouco discutido dentro da sala de aula, e pouco abordado dentro das instituições de saúde, sendo ela pública ou privada ${ }^{9}$.

$O$ reconhecimento da enfermagem, que o cuidado e acolhimento não é apenas práticas curativas e medicamentosas, desde sua formação, é fundamental para efetivar e aumentar o número de denúncia, oferecendo uma equipe multidisciplinar que dê suporte a vítima, e ao profissional esclarecendo dúvidas de como agir frente aos casos de violência contra mulher, oferecendo segurança e apoio intersetorial ${ }^{13}$. As mulheres que sofrem violência devem ter seus direitos garantidos por lei de acesso a saúde de forma integral.

\section{Considerações Finais}

O presente estudo demonstrou a importância do acolhimento de enfermagem à mulher vítima de violência, contudo evidenciou que os profissionais de enfermagem, no geral, ainda se encontram despreparados para atender às mulheres vitimas de violência doméstica de forma acolhedora e humanizada, deixando assim de garantir o direito à saúde de forma integral.

Desta forma, entende-se que este estudo aponta para a urgência de se efetivar na prática, a capacitação de profissionais de enfermagem e todos os profissionais da área de saúde. É necessário investimento em equipe multidisciplinar que atenda e direcione as vítimas a locais seguros e confortáveis.

A mulher ainda sofre muito preconceito diante de uma sociedade machista, enraizada numa cultura patriarcal, que desvaloriza a mulher colocando em posição inferior pelo simples fato de ser mulher. É fundamental mudança nas políticas públicas, fortalecimento de projetos sociais que possibilitem a inserção social dessas mulheres no mercado de trabalho, contribuindo para o rompimento das relações adoecedoras e o ciclo de violência.

A mulher que sofre violência doméstica não se encontra na situação de violência por opção, ela procura por diversas vezes o serviço de saúde, se encontra fragilizada, desamparada, constrangida, envergonhada, com medo das reações do agressor, sofre por anos calada as agressões que podem ser físicas, psicológicas ou sexuais. Assim, as ações efetivas de fortalecimento e empoderamento da mulher, são essenciais para o enfrentamento da violência doméstica.

\section{Referências}

1. Santos $W$ J, Oliveira P P, Viegas SM F, Ramos TM, Policampo A G, Silveira E A A. 
Violência Doméstica Contra a Mulher Perpetrada por Parceiro Íntimo: Representações Sociais de Profissionais da Atenção Primária à Saúde Doméstica Revista Cuidado é Fundamental online, Rio de Janeiro jul. / set. 2018.

2. Mafiolettil T M, Peresl A M, Laroccal L $M$, Fontoural $M \quad P$. Violência conta mulher :trajetoria historica de um programa de atenção Primaria. Revista Brasileira de Enfermagem Reben, Curitiba, 2018.

3. Peralva TR, Araújo A K C, Bezerra C S, Souza D O, Rafael L C, Melo RA. Violência Doméstica na percepção de enfermeiros de serviço de Emergência. Revista Portuguese ReonFacema. Pernambuco, setembro 2016.

4. Lucena K D T, Deininger LSC, Coelho $\mathrm{H}$ FC, Monteiro ACC, Vianna RPT, Nascimento JA. Análise do ciclo de violência doméstica contra mulher. Hum Growth Dev, Maceio, p. 139 a 146, 2016.

5. Viana AL, Carvalho MOS, Vieira MCA, Sarmento SS, Souza APL Violência contra Mulher. Revista de Enfermagem UFPE On Line, Recife, v. 4, abril 2018.

6. Rodrigues PV, Oliveira LG, Machado CJ ,Simões VA, Pires MMMV, Morai LGLR Assistencia a saúde da mulher em situacão de violência doméstica. Revista Saude.Com, Bahia , v. 14, 2018.

7. Netto L A, Pereira ER, Tavares JMAB, Ferreira DC, Broca PV. Atuação da Enfermagem na Conservação da saúde das Mulheres em situção de Violência. Rev.Mim Efermagem, Rio de Janeiro, janeiro 2018.

8. Garcia L P. A magnitude invisível da violência contra a mulher. Revista Epidemiol. Serv. Saúde, Brasília, julho 2016.

9. Freitas $\mathrm{R}$ JM, Sousa VB, Costa TSC, Feitosa RMM, Monteiro ARM, Moura NA. Atuação dos enfermeiros na identificação e notificação dos casos de violência contra a mulher. Revista Juiz de Fora, Fortaleza, v. 43, p. 91 a 97, abril 2017.

10. Cordeiro CC, Santos RM, Gomes NP, Melo DS, Mota R S, Couto TM . Formação profissional e notificação da violência contra a mulher. Revista Baiana de Enfermagem, Salvador, v. 29, n. 3, p. 209-217, jul./set.2015.
11. Lopes JS. Humanização do Acolhimento a mulher Vítima de Violência Doméstica:Revisao Sistematica a partir da promugação da lei maria da penha. Rev Gênero e Direito, Paraiba, v. 5, 2016.

12. Borburemaa TLR, Pachecoa AP, Nunesb $\mathrm{AA}$, Moréc $\mathrm{CL} \mathrm{O}$, Krenkel $\mathrm{S}$. Violência conta mulher em contexto de vulnerabilidade social na atenção Primaria ;Registro de violencia em prontuario. Revista Brasileira de Medicina Familia e Comunidade, Rio de Janeiro, dezembro 2017.

13. Acosta DF, Gomes VLO, Oliveira D C, Gomes GC, Fonseca A D. Aspectos Eticos no cuidado de Enfermagem as Vitímas de Violência Doméstica. Texto Contexto Enferm, Rio de Janeiro.2017.

14. Hasse M, Vieira E M. Como os profissionais de saúde atendem mulheres em situação de violência? Uma análise triangulada de dados. Revista Saúde Debate. Rio de janeiro, v. 38, n. 102, p. 482-493, jul-set 2014.

15. Batista AC, Divino AEA, Martins MCV. A Sistematização da assistencia de Enfermagem no atendimento a mulher vítima de violência. Caderno de Graduação, Aracaju, v. 4, n. 3, p. 113 a 122, Abril 2018.

16. Peralva TR, Araújo AKC, Bezerra CS, Souza DO, Rafael LC, Melo RA. Violência doméstica na percepção de enfermeiros de serviço de emergência. Revista Portuguese ReonFacema. Pernabuco Jul-Set; 2(3): 221-228. . 2016.

\section{Endereço para Correspondência}

Faculdade Metropolitana de Camaçari

Av. Jorge Amado, s/no, Bairro Ponto Certo -

Camaçari (BA)

CEP.: $42801-170$

amanda_marias@yahoo.com.br

Recebido em 03/09/2020

Aprovado em 27/02/2021

Publicado em 06/04/2021 